\title{
Effects of Electroacupuncture on Ovarian Expression of the Androgen Receptor and Connexin 43 in Rats with Letrozole-Induced Polycystic Ovaries
}

\author{
Ge Xu $\mathbb{D}^{1},{ }^{1}$ Andong Zhang $\mathbb{D},{ }^{2}$ Jiandang Liu $\mathbb{D},{ }^{1}$ Xi Wang, ${ }^{2}$ Jiwei Feng, ${ }^{1}$ and Yuelai Chen $\mathbb{D}^{1}$ \\ ${ }^{1}$ Shanghai University of Chinese Traditional Medicine, Shanghai 201203, China \\ ${ }^{2}$ Yueyang Hospital of Integrated Traditional Chinese and Western Medicine, Shanghai University of Chinese Medicine, \\ Shanghai 200437, China
}

Correspondence should be addressed to Yuelai Chen; chenyuelai@163.com

Received 4 February 2020; Revised 28 May 2020; Accepted 19 June 2020; Published 14 July 2020

Academic Editor: Michel Mansur Machado

Copyright (C) $2020 \mathrm{Ge} \mathrm{Xu}$ et al. This is an open access article distributed under the Creative Commons Attribution License, which permits unrestricted use, distribution, and reproduction in any medium, provided the original work is properly cited.

Background. Polycystic ovarian syndrome (PCOS) occurs in women of reproductive age and is often characterized by reproductive and endocrine dysfunction. Androgens play a major role in PCOS, and previous studies reported abnormal expression of Connexin $43(\mathrm{Cx} 43)$ in animal models of PCOS, suggesting an association of Cx43 with PCOS pathogenesis. Experimental and clinical evidence indicated that acupuncture may be a safe and effective approach for treating reproductive and endocrine disorders in women with PCOS. This study aimed to determine the effects of electroacupuncture (EA) on PCOS and its relationship with the expression of the androgen receptor (AR) and Cx43. Methods. In total, 30 female Sprague Dawley rats (6 weeks old) were randomly divided into three groups: control group, letrozole (LE) group, and LE + EA group. Rats were administered LE solution $(1.0 \mathrm{mg} / \mathrm{kg})$ for 21 consecutive days to induce PCOS. For the LE + EA group, additional EA treatment was conducted $(2 \mathrm{~Hz}, 20 \mathrm{~min} / \mathrm{d})$ with "Guanyuan" (CV3) for 14 consecutive days. After hematoxylin-eosin staining, the ovarian structure was observed with an optical microscope, and serum levels of the following hormones were examined via enzyme-linked immunosorbent assay (ELISA): testosterone ( $\mathrm{T})$, estradiol $\left(\mathrm{E}_{2}\right)$, sex hormone-binding globulin (SHBG), follicle-stimulating hormone (FSH); luteinizing hormone (LH), insulin (INS), anti-Müllerian hormone (AMH), and inhibin B (INHB). Fasting blood glucose (FBG) levels were evaluated using glucose oxidase-peroxidase. Ovarian mRNA and protein expressions of AR and Cx43 were determined by real-time RT-PCR and Western blot analysis. Results. EA was found to restore the cyclicity and ovarian morphology in the PCOS rat model. Serum derived from the LE + EA group showed significant decreases in the levels of T, free androgen index (FAI), LH, LH/FSH ratio, AMH, INHB, and fasting serum insulin (FINS), and significant increases in the levels of $\mathrm{E}_{2}, \mathrm{FSH}$, and SHBG. Western blot analysis showed a decreased protein expression of ovarian AR and Cx43; real-time RT-PCR showed reduced expression of ovarian mRNA levels of AR and Cx43. Conclusions. In conclusion, our results showed that EA can ease hyperandrogenism and polycystic ovary morphology in PCOS rats. Furthermore, EA counteracted the letrozole-induced upregulation of $\mathrm{AR}$ and $\mathrm{Cx} 43$. These results suggested that acupuncture can break the vicious cycle initiated by excessive androgen secretion and may be an effective treatment method for improving the reproductive and endocrine dysfunction caused by PCOS.

\section{Background}

Polycystic ovarian syndrome (PCOS) is a group of syndromes with multiple pathogenesis and clinical polymorphism and an endocrine and metabolic disorder in women. Reported PCOS incidence ranges from $6 \%$ to $20 \%$ in different areas, depending on the criteria used [1-4]. Its phenotypic expression varies and is characterized by ovulatory dysfunction, infertility, hirsutism, and obesity [5]. Histological analyses have shown numerous antral follicles in PCOS patients. However, the etiology of this heterogeneous condition remains unknown. However, there is evidence that human PCOS is associated with hyperandrogenism, hyperinsulinemia, and insulin resistance 
(IR), hypothalamus-pituitary-ovarian axis dysfunction, and progression to type II diabetes $[6,7]$. The proliferation of follicular thecal cells and overproduction of androgens are the primary causes of the pathological manifestations of PCOS [8].

Studies have shown that acupuncture may be a safe and effective way to treat reproductive endocrine dysfunction in women with PCOS [9]. At present, there are many clinical reports on acupuncture treatment of PCOS, and most of these studies confirmed the effect of acupuncture, reporting that acupuncture can improve at least one or several symptoms or indicators in PCOS [10]. Acupuncture can improve the egg quality of women with PCOS undergoing in vitro fertilization and embryo transfer (IVF-ET) and improve the clinical pregnancy rate of IVF [11]. However, it is also believed that acupuncture has no obvious effect on PCOS [12].

In several studies, it has been shown that repeated lowfrequency EA rehabilitated estrous cyclicity and regulated gonadotropin-releasing hormone and AR expression in the hypothalamus of rats, regulated $\mathrm{u}, \mathrm{K}$ receptor mRNA expression, and lowered testosterone levels, while manual stimulation can reduce estrogen, progesterone, and kisspeptin receptor expression $[13,14]$. EA regulated circulating gonadotropin levels in PCOS mice, independent of the effects of sex hormones or $\beta$-epinephrine, and affected the ovarian adiponectin system [15]. In rats with estradiol valerate-induced PCOS, the concentration of $\beta$-endorphins in the hypothalamus and plasma was significantly lower than that found in control rats, and treatment with EA significantly increased the concentration of $\beta$-endorphins in the hypothalamus [16]. In a previous study, it was found that EA could improve the local androgen excess environment in the ovaries by regulating protein and mRNA expression of $\mathrm{P} 450$ arom and $\mathrm{P} 450 \mathrm{c} 17 \alpha$ in the ovarian tissue of rats with PCOS and by improving the reproductive endocrine and metabolic disorders associated with PCOS [17]. Compared with the physiotherapy group, 10-13 weeks of EA intervention improved the ovulation frequency of women with PCOS and regulated serum sex hormone levels [18].

The prevalence of IR and hyperinsulinemia in PCOS patients is $50 \%-70 \%$ [19]. This prevalence is higher in overweight women and reaches 95\% [20]. Acupuncture may improve IR by increasing the number and affinity of insulin receptors in obese individuals. In addition, it has been shown that EA does not rely on insulin to stimulate glucose conversion in skeletal muscles and enhances insulin sensitivity during glucose conversion in rats. Furthermore, EA has been reported to restore the expression of leptin and uncoupling protein 2 and to increase plasma levels of insulin-like growth factor-1 [21-24].

Androgen plays its role by binding to the AR. The AR is widely expressed in granulosa cells at the early stage of follicular development, and ARs are abundant in preantral follicles [25]. With the development of follicles, AR expression in granulosa cells gradually decreases and reaches a minimum level before ovulation [26]. The differential expression of $\mathrm{AR}$ at different times ultimately affects the follicular outcomes by coregulating multiple mechanisms inside and outside the ovary.
In mice, most follicles in the ovaries of mice lacking Connexin $43(\mathrm{Cx} 43)$ stop developing before granulosa cell stratification, resulting in an abnormal follicular structure, vacuolization of oocytes and granulosa cells to a certain extent, inability to resume oocyte meiosis, and the inability of the oocyte to be fertilized [27, 28]. This is mainly because the lack of $\mathrm{Cx} 43$ results in the inability to establish communication, material exchange, and signal transduction between granulosa cells, and eventually failure of granulosa cell proliferation and stratification. In addition, in several studies, it was found that $\mathrm{Cx} 43$ can resist granulosa cell apoptosis, promote follicular selection and recruitment, and its expression intensity is negatively correlated with the apoptotic index of granulosa cells $[29,30]$. Cx43 plays an important role in the process of oocyte meiosis and follicular selection. In recent years, studies have found abnormal expression of $\mathrm{Cx} 43$ in PCOS animal models, suggesting that Cx43 may be associated with PCOS pathogenesis [31]. In testosterone-treated mouse ovaries, the location and quantity of AR and Cx43 were significantly changed, with the expression of AR significantly being increased, whereas the expression of Cx43 was significantly decreased [32]. However, in another study, it was shown that the expression of $\mathrm{Cx} 43$ protein was increased in androstenedione-induced polycystic ovaries of rats and androstenedione upregulated Cx43 protein levels in granulosa cells in vitro [33]. In addition, it was found that the AR pathway plays an important role in the regulation of $\mathrm{Cx} 43$ expression in prostate cancer cells. AR may be the upstream signal of Cx43 [34]. However, it is not clear whether EA has any effect.

Previous studies have demonstrated that letrozole-induced PCOS models have characteristics similar to those of human patients, such as hyperandrogenism, LH hypersecretion, follicular dysplasia, and anovulation [35]. In our previous study, we compared the efficacy of different acupoints and selected the one with the best therapeutic effects on hyperandrogenism among four groups (ST36, SP6, CV3, and comprehensive groups) [36]. In this study, we attempted to gain a deeper understanding of the effects of EA on PCOS and its relationship with $\mathrm{AR}$ and $\mathrm{Cx} 43$ expression using a letrozole-induced PCOS model in rats.

\section{Methods}

2.1. Animals and Experimental Procedure. In this study, 30 female Sprague Dawley rats (6 weeks old) were housed in a controlled temperature environment $\left(20-23^{\circ} \mathrm{C}\right)$, humidity (40\%-60\%), and $12 \mathrm{~h}$ light : $12 \mathrm{~h}$ dark cyclical alternates with ad libitum availability of food and water. All procedures described here were approved by the Animal Ethical Committee of Shanghai University of Chinese Traditional Medicine (Shanghai, China).

Thirty rats with comparable weights $(160 \pm 20 \mathrm{~g})$ were randomly assigned to three different groups: control group, $\mathrm{LE}$ group, and LE group receiving EA (LE + EA group). The PCOS model was established by administering (via gavage) the animals letrozole solution $(1.0 \mathrm{mg} / \mathrm{kg})$ once daily for 21 consecutive days. The control group was administered $1 \%$ CMC $(10 \mathrm{mg} / \mathrm{kg})$ by gavage. During modeling, rats were 
weighed using a JA 31002 electronic balance (Shanghai Jing Tian Electronic Instrument Co., Ltd., Shanghai, China). From the second day after modeling, the LE + EA group underwent EA treatment for 14 consecutive days. The control and LE groups were not given any treatment, except for fixation.

\subsection{Estrus Cyclicity Was Observed Using a Microscope.} Estrus cyclicity was monitored daily at 9 AM from the first day after the first administration to the $36^{\text {th }}$ consecutive day by microscopic observation of the type of epithelial cells in the vaginal smear. Vaginal cells were collected via saline lavage, fixed with methanol, and stained with Pap stain. Animals with regular 4-5-day cycles, including proestrus, estrus, postestrus, and diestrus, were defined as normal cyclic rats, whereas those whose estrus cycles stopped for four consecutive days in diestrus phases were termed acyclic rats.

2.3. EA Treatment. In the LE +EA group, acupoints CV-3 (on the ventral midline at approximately the upper $3 / 5$ and lower $2 / 5$ of the line) and the point $5 \mathrm{~mm}$ next to CV-3 at the same horizontal axis were used. We inserted $25 \mathrm{~mm}$ acupuncture needles $(\phi 0.22)$ to a depth of $0.3-0.5 \mathrm{~cm}$ and attached them bilaterally to the Hwato SDZ-II electroacupuncture therapeutic apparatus (Suzhou medical Appliance factory, Suzhou, China). The points were electrically stimulated with a low frequency of $2 \mathrm{~Hz}$, thereby adjusting the intensity to $2 \mathrm{~mA}$. The retention time was $20 \mathrm{~min}$. Rats were treated daily for 14 consecutive days.

2.4. Blood and Tissue Collection. On the day after the last EA treatment, the vaginal smears were examined before sampling. We collected blood samples and ovarian tissue samples on the diestrus stage of the estrus cycle and between 8 and 11 AM. Rats that were not on diestrus that day were sampled on a different day when they entered diestrus. Rats were anesthetized with $3 \%$ pentobarbital sodium $(0.1 \mathrm{ml} /$ $100 \mathrm{~g}$ of body weight), and then blood samples were obtained from the abdominal aorta after overnight fasting. Blood samples were then centrifuged at $3000 \mathrm{~g}$ for $15 \mathrm{~min}$ at $4^{\circ} \mathrm{C}$, and serum was stored at $-80^{\circ} \mathrm{C}$. Subsequently, ovarian dissection was performed rapidly on ice. The wet weight of the dissected ovaries was measured using BS 124S electronic balance (Sartorius, Göttingen, Germany); from each rat, the left ovary was fixed in $4 \%$ paraformaldehyde for histological examination, and right ovary was stored at $-80^{\circ} \mathrm{C}$ until extraction.

2.5. Morphological Analysis. From each rat, ovarian tissue was collected after blood collection, fixed in $4 \%$ paraformaldehyde, blocked in paraffin, and cut into serial $4 \mu \mathrm{m}$ sections. Sections were stained with hematoxylin-eosin and examined using a Leica DM 2000 microscope (Leica, Wetzlar, Germany).
2.6. Blood Sample Assays. Serum concentrations of $\mathrm{T}, \mathrm{E}_{2}$, FSH, LH, SHBG, AMH, INHB, and FINS were quantified using rat ELISA Kits (Abcam Systems, Cambridge, UK). All experiments were performed following the manufacturer's instructions. The detection limit was $1.0 \mathrm{pg} / \mathrm{mL}$ for $\mathrm{T}$, $0.1 \mathrm{pmol} / \mathrm{L}$ for $\mathrm{E}_{2}, 0.1 \mathrm{IU} / \mathrm{L}$ for $\mathrm{FSH}, 0.1 \mathrm{mIU} / \mathrm{L}$ for $\mathrm{LH}$, $0.1 \mathrm{nmol} / \mathrm{L}$ for SHBG, $10 \mathrm{pg} / \mathrm{mL}$ for AMH and INHB, and $0.1 \mathrm{mU} / \mathrm{L}$ for FINS. For all ELISA Kits, the intra- and interassay variations were $10 \%$ and $15 \%$. FBG levels were determined using a glucose oxidase kit (Rongsheng Biotech, Shanghai, China).

2.7. RNA Isolation and Real-Time RT-PCR. Total RNA was isolated using TRIsoln reagent (Invitrogen, Carlsbad, CA, USA), and total RNA ( $2 \mu \mathrm{g}$ ) was reverse transcribed using the Superscript Reverse Transcriptase kit (Takara, Japan). Further, real-time PCR was performed with a TB Green ${ }^{\mathrm{TM}}$ Premix Ex Taq ${ }^{\mathrm{TM}}$ (Takara, Japan) using an ABI 7900 real-time PCR system and SDS software (Applied Biosystems, Foster City, CA, USA). Primers were procured from Sangon (Sangon Biotech, Shanghai, China) and sequences are shown in Table 1. The mRNA expression values for each sample were calculated following the ${ }^{\Delta \Delta} \mathrm{Cq}$ method.

2.8. Western Blot Analysis. We homogenized each group of rat ovaries in ice-cold RIPA Lysis Buffer (Beyotime, Shanghai, China). Then, sample homogenates were incubated on ice for $30 \mathrm{~min}$ and centrifuged $(13200 \mathrm{~g})$ for $15 \mathrm{~min}$ at $4^{\circ} \mathrm{C}$. The supernatants were collected, and protein concentration was determined using the BCA Protein Assay Kit (Beyotime, Shanghai, China) and stored at $-80^{\circ} \mathrm{C}$ until electrophoresis. The samples were denatured by adding the sample buffer $(1.0 \mathrm{~mol} / \mathrm{L}$ Tris- $\mathrm{HCl}(\mathrm{pH} 6.8 ; 0.6 \mathrm{ml}), 50 \%$ glycerol $(5 \mathrm{~mL}), 10 \%$ SDS $(2 \mathrm{~mL}), \beta$-mercaptoethanol $(0.5 \mathrm{ml}), 1 \%$ bromophenol blue $(1 \mathrm{~mL})$, and deionized water to make the total volume to $10 \mathrm{~mL})$. Total protein $(30 \mu \mathrm{g})$ was separated on 10\% SDS-PAGE gels in Tris-glycine and 0.1\% SDS buffer and transferred to a nitrocellulose sheet in $25 \mathrm{~mm}$ Tris, $192 \mathrm{~mm}$ glycine, and 20\% methanol buffer at $200 \mathrm{~mA}$ for $2 \mathrm{~h}$. Membranes were blocked for $2 \mathrm{~h}$ at room temperature in $5 \%$ nonfat dry milk and incubated overnight at $4^{\circ} \mathrm{C}$ with an anti-androgen receptor antibody (Abcam, Cambridge, UK) or anti-Cx43 antibody (Abcam, Cambridge, UK) at $1 / 200$ or $1 / 1000$ dilutions, respectively. Then, imprints were washed and incubated for $2 \mathrm{~h}$ at room temperature with a secondary antibody bound to horseradish peroxidase (HRP) (1:5000, Abcam, Cambridge, UK). The protein-antibody complexes were then visualized using ECL Plus Western Blot Detection Reagents (GE Healthcare, Pittsburgh, PA, USA) and photographed with Clinx ChemiScope Mini Series Western Blot Imaging System (CLINX Science Instruments, Shanghai, China). Protein signals were quantified using the ImageJ software. $\beta$-Actin or Gapdh served as a loading control and an internal reference.

2.9. Statistical Analysis. Experimental data are shown as the mean \pm SEM, and statistical analyses were performed using 
TABle 1: Primer sequences of targeted genes in rats.

\begin{tabular}{lccc}
\hline Targeted genes & Forward and reverse primers & Amplification size (bp) & Accession number \\
\hline AR & $\begin{array}{l}\text { TTTTGAGTTTTGTTGTATT } \\
\text { CTCTCTCTGTTTGTTTCTT }\end{array}$ & 173 & NM_012502 \\
\hline Cx43 & $\begin{array}{l}\text { CCACTCTCGCCTATGTCTCC } \\
\text { TAGTTCGCCCAGTTTTCTC }\end{array}$ & 110 & NM_012567 \\
\hline Gapdh & $\begin{array}{l}\text { TCCTGCACCACCAACTGCTTAG } \\
\text { AGTGGCAGTGATGGCATGGACT }\end{array}$ & 102 & NM_017008 \\
\hline
\end{tabular}

the SPSS software package (SPSS, version 20.0; Chicago, IL, USA). Differences between groups were evaluated using one-way analysis of variance (ANOVA). The LSD test was used for pairwise comparison of homogeneity of variance, and Dunnet's test was used for heterogeneity of variance. $P<0.05$ was considered significant.

\section{Results}

3.1. Improvement in Estrous Cyclicity. After modeling, rats administered letrozole displayed abnormal estrous cycles with estrus disappearing on approximately the 12th day and remained in the diestrus stage. All rats in the control group showed normal estrous cyclicity. Thus, the model animal was successfully established. In the LE + EA group, 7 of 10 rats resumed estrous cyclicity, and epithelial keratinocytes in vaginal smear were observed under a microscope during treatment. The remaining 3 rats in this group showed no response to EA treatment until the time of terminal kill. The 10 rats in the LE group were still in the diestrus stage at the time of the terminal kill.

3.2. Rat Body Weight and Ovary Weight. No significant differences were observed in the initial body weight between groups. From the 5th day after modeling to the end of modeling, the increase in body weight of rats in each modeling group was significantly faster when compared to that in the control group (Figure 1(a)), and the body weight was higher in the modeling groups compared to that in the control group at the end of modeling $(P<0.01$; Figure $1(b))$. This conforms to the characteristics of PCOS model rats. Following EA treatment, the body weight of rats in the $\mathrm{LE}+\mathrm{EA}$ group was reduced compared with that of rats in the LE group $(P<0.05$; Figure $1(\mathrm{c}))$.

The ovarian weight of rats in the LE group significantly increased compared with that of rats in the control group $(P<0.01)$. In addition, the ovarian weight of rats in the LE + EA group decreased significantly when compared with that of rats in the LE group $(P<0.01)$ (Figure $1(d))$.

3.3. Ovarian Morphological Changes. In the control group, corpus luteum and follicles at different stages of development were observed. Granulosa cells were arranged in multiple layers within follicles. In the LE group, the surface of the ovary was pale and the capsule was thickened, with cystic follicles protruding. Microscopically, the number of granulosa cell layers in the LE group sections was less, and oocytes and radiating crowns disappeared in the cystic follicles.

Compared with the LE group, the LE+EA group showed a decrease in ovary size as well as a decrease in the number of cystic follicles. Furthermore, an increase in the granulosa cell layer of follicles was observed in the LE + EA group, and submature follicles with cumulus were observed (Figure 2).

3.4. Circulating Hormone Level. Testosterone levels were significantly elevated in the LE group $(P<0.01)$ with a decrease in SHBG levels $(P<0.01)$, resulting in a higher FAI $(P<0.01)$ in rats with PCOS compared with the control group. After EA treatment, levels of circulating testosterone were lower, and SHBG levels were higher in the LE + EA group compared to the LE group, whereas FAI was lower in $\mathrm{LE}+$ EA group compared to the LE group $(P<0.01)$.

Estradiol levels were significantly decreased in the LE group $(P<0.01)$ compared with the control group. After EA treatment, levels of circulating estradiol were higher in $\mathrm{LE}+$ EA group compared to the LE group $(P<0.01)$.

Levels of circulating LH were higher and FSH levels were lower in the LE group compared with those in the control group $(P<0.01, P<0.01)$, resulting in a higher LH/FSH ratio $(P<0.01)$ in rats with PCOS. EA treatment decreased LH $(P<0.01)$ and increased FSH in the LE + EA group $(P<0.01)$. Furthermore, the LH/FSH ratio was lower in the $\mathrm{LE}+\mathrm{EA}$ group compared to the LE group $(P<0.01)$ (Figure 3).

3.5. Circulating Levels of $A M H$ and INHB. Levels of circulating $\mathrm{AMH}$ and $\mathrm{INHB}$ were increased in the LE group $(P<0.01)$ compared with the control group, and EA treatment decreased AMH and INHB levels in the LE + EA group $(P<0.01)$ (Figure 4$)$.

3.6. Levels of FINS and FBG and Homeostasis Model-Insulin Resistance (HOMA-IR). Compared with the control group, the LE group showed increases in FINS, FBG, and HOMAIR $(P<0.05, P<0.01)$. After EA treatment, levels of circulating insulin were decreased in the LE + EA group compared with the LE group $(P<0.05)$. In addition, FBG levels were similar between $\mathrm{LE}$ and $\mathrm{LE}+\mathrm{EA}$ groups $(6.74 \pm 0.91 \mathrm{mmol} / \mathrm{L}, \quad 6.79 \pm 0.36 \mathrm{mmol} / \mathrm{L})$. In addition, HOMA-IR tended to be lower in the LE+EA group; however, the difference was not significant (Figure 5). 


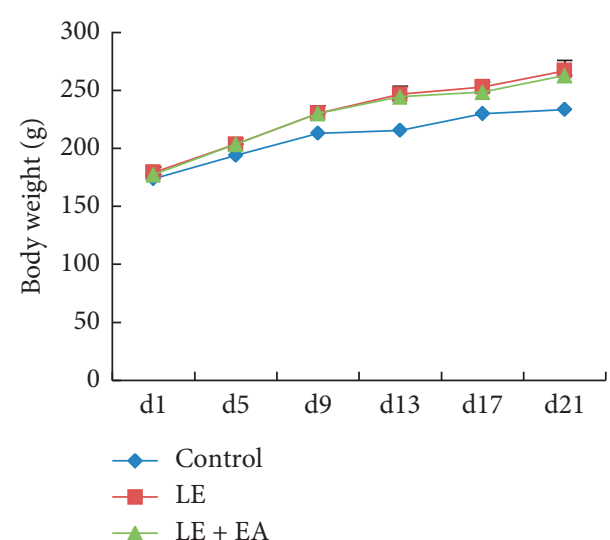

(a)

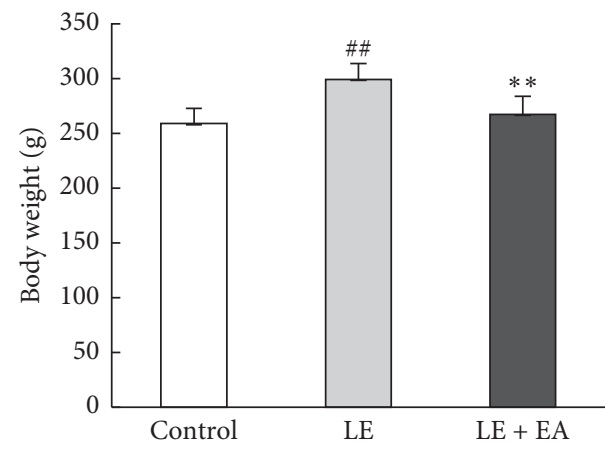

(c)

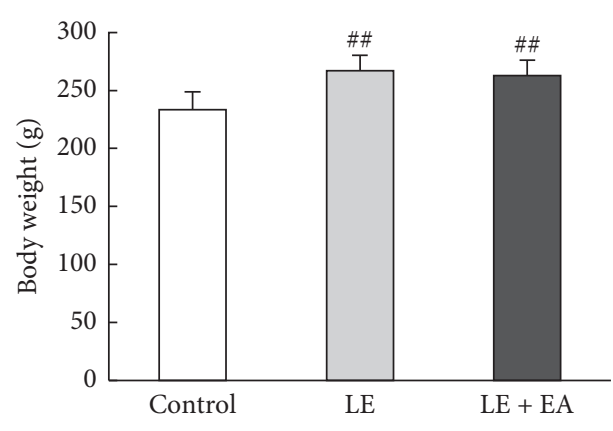

(b)

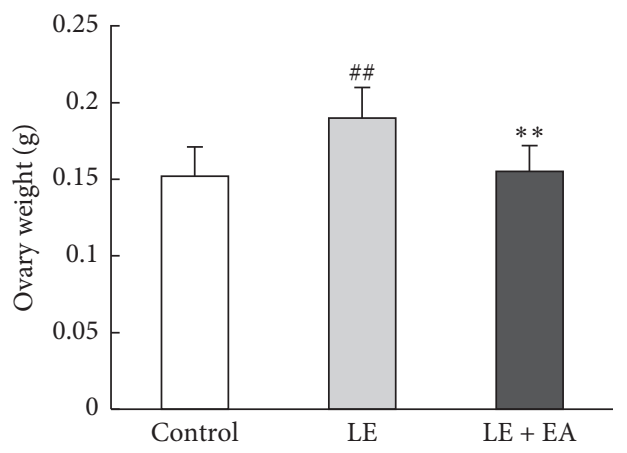

(d)

Figure 1: Body weight and ovarian weight of rats. (a) Changes in body weight during modeling. (b) Pretreatment body weight (on the 21st day). (c) Posttreatment body weight. (d) Ovary weight. Error bars represent the SEM. $n=10$ per group. \#P<0.05; \#\# $P<0.01$ vs control group; $* * P<0.01$ vs LE group.

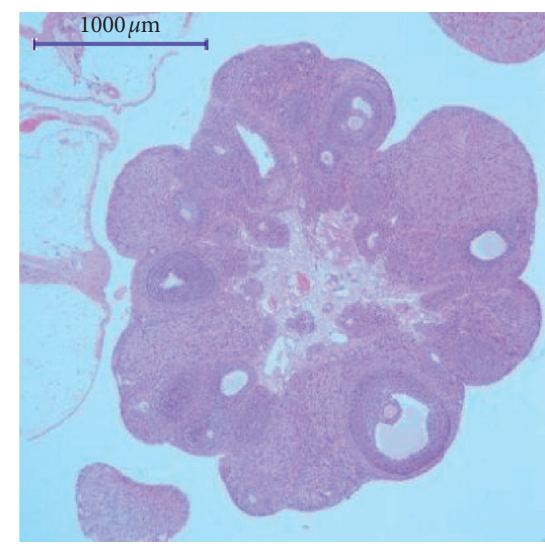

(a)

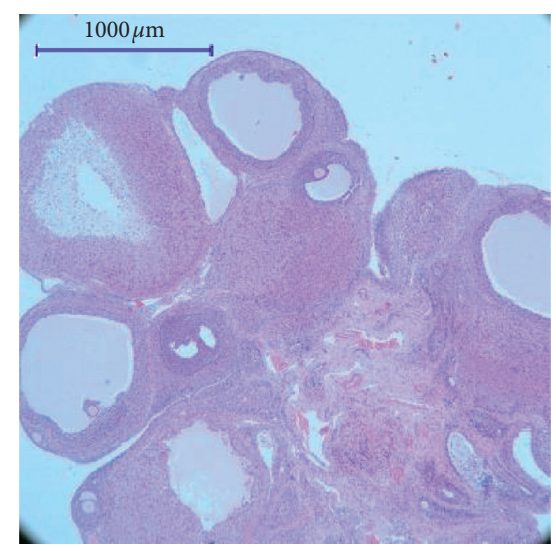

(b)

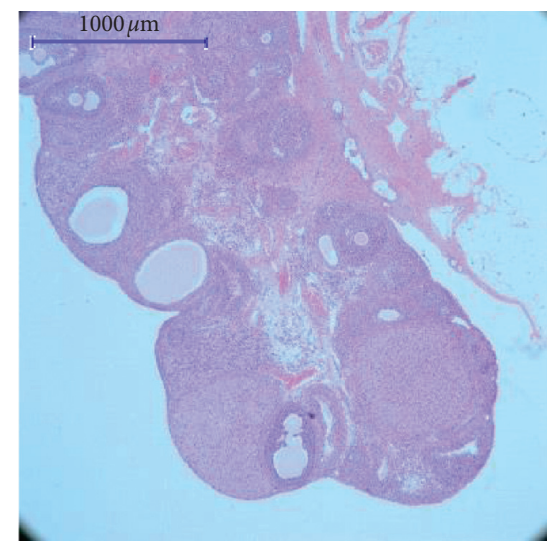

(c)

FIgURE 2: Histology of ovaries. Ovaries were stained with hematoxylin and eosin: (a) control group; (b) LE group; (c) LE + EA group; magnification $\times 400$. Scale bars represent $1000 \mu \mathrm{m}$ in each case.

\subsection{Immunolocalization and Expression of $A R$ and $C x 43$ in} Control Rat Ovary. To investigate the localization and expressions of AR and $\mathrm{Cx} 43$ in the rat ovary, immunofluorescence was performed on samples in the control group. As shown in Figure 6, AR was expressed in the nuclei of granulosa cells and theca cells (TCs) in ovarian follicles at every developmental stage, with the highest expression levels found in granulosa cells (GCs) of preantral and small antral follicles. The expression of AR decreased when follicles entered the preovulation stage. In addition, $\mathrm{Cx} 43$ was expressed on the borders of GCs of small and large follicles and the corpus luteum (CL). Cx43 was observed between 


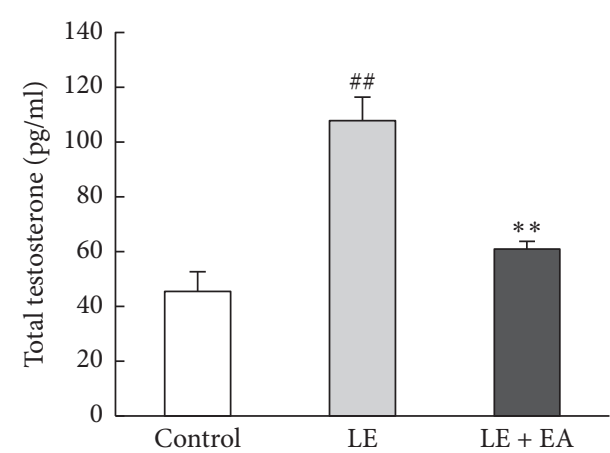

(a)

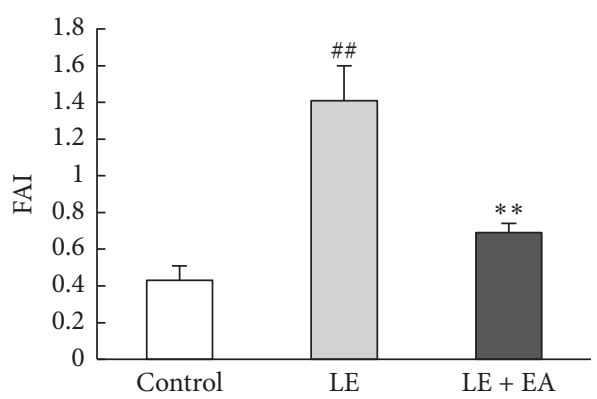

(c)

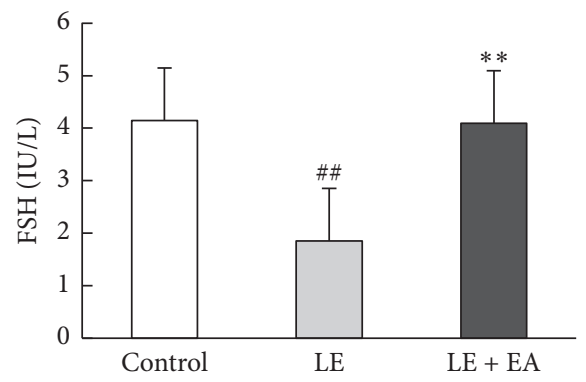

(e)

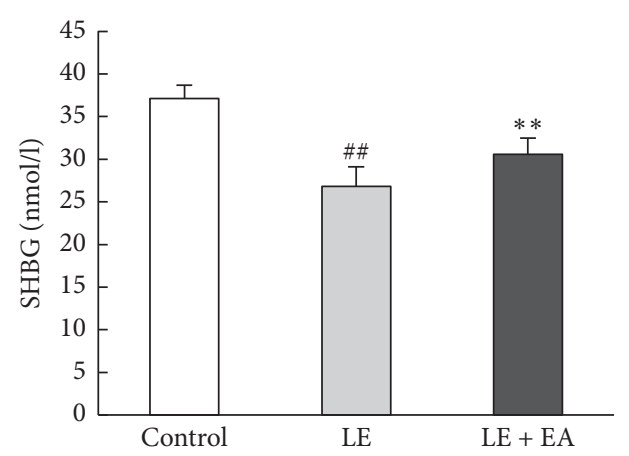

(b)

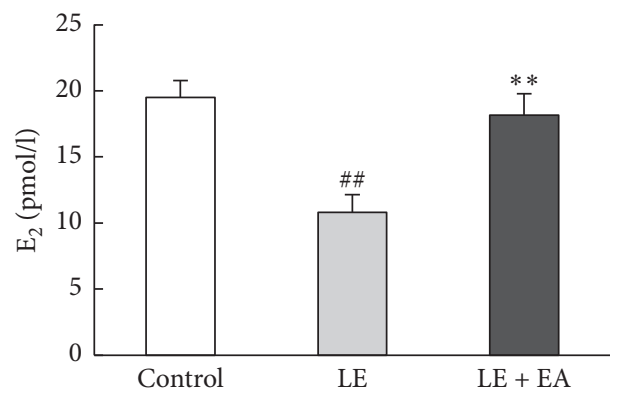

(d)

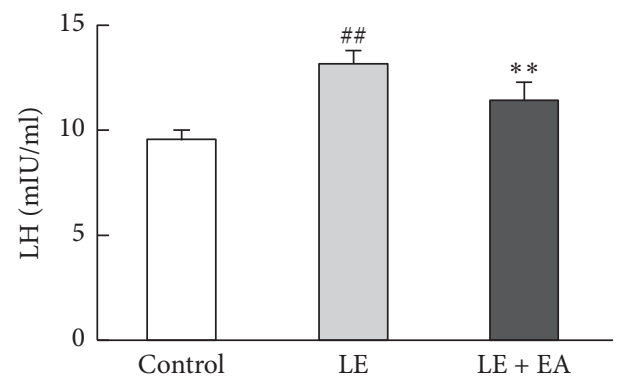

(f)

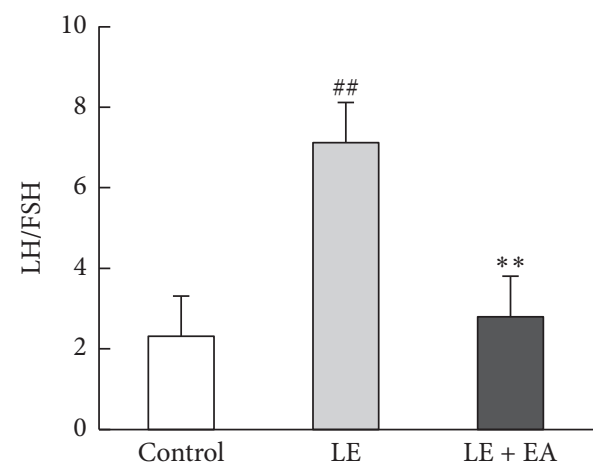

(g)

Figure 3: (a) Serum levels of testosterone T, (b) sex hormone-binding globin (SHBG), (c) fasting serum insulin (FAI), (d) estradiol (E $\mathrm{E}_{2}$ ), (e) follicle-stimulating hormone (FSH), (f) luteinizing hormone ( $\mathrm{LH})$, and (g) LH/FSH in rats. Error bars represent SEM, $n=10$ per group. $\#$ \# $<0.01$ vs control group; $* * P<0.01$ vs LE group.

granulosa cells as well as between granulosa cells and oocytes in large antral follicles and preovulatory follicles. Cx43 was hardly detected at the thecal cell layer.
3.8. Ovarian mRNA Expression of $A R$ and Cx43. Ovarian mRNA expression of AR and Cx43 was higher in the LE group compared to the control group $(P<0.01)$. In addition, 


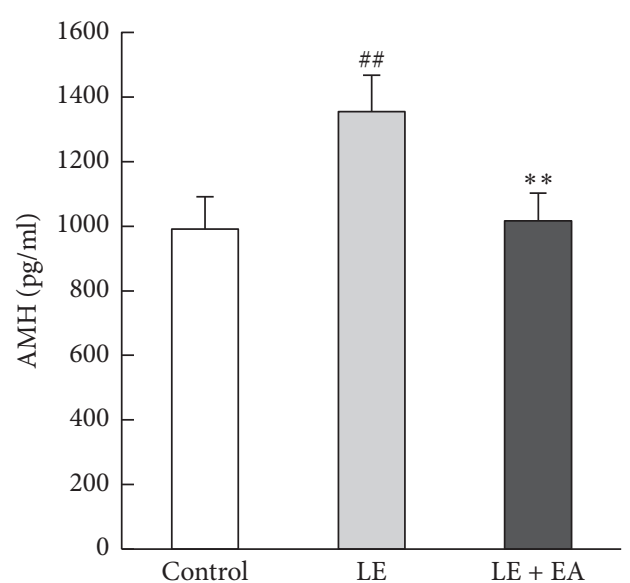

(a)

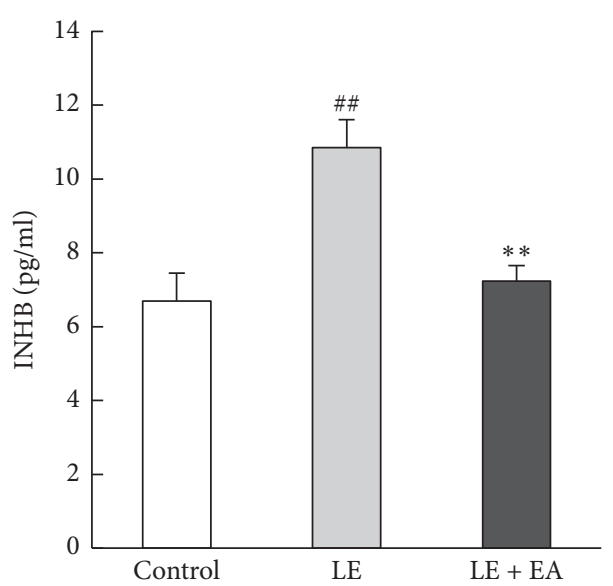

(b)

Figure 4: (a) Serum levels of anti-Müllerian hormone (AMH) and (b) inhibin B (INHB) in rats. Error bars represent the SEM, $n=10$ per group. \#\# $P<0.01$ vs control group; $* * P<0.01$ vs LE group.

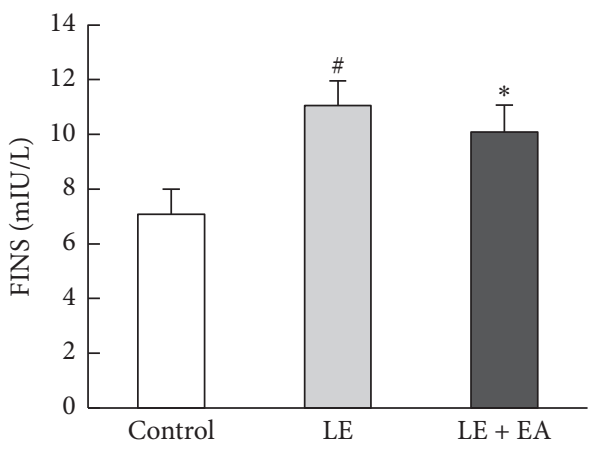

(a)

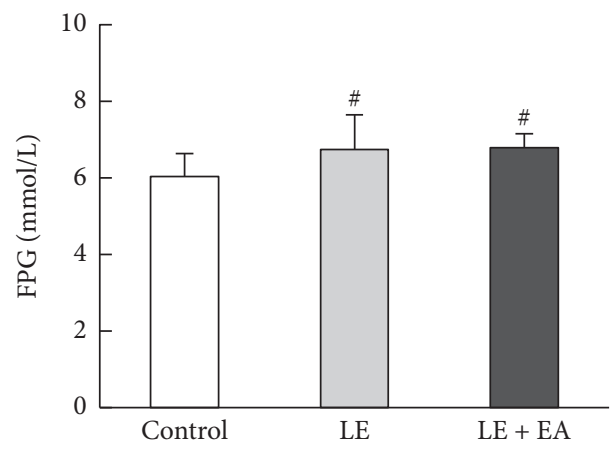

(b)

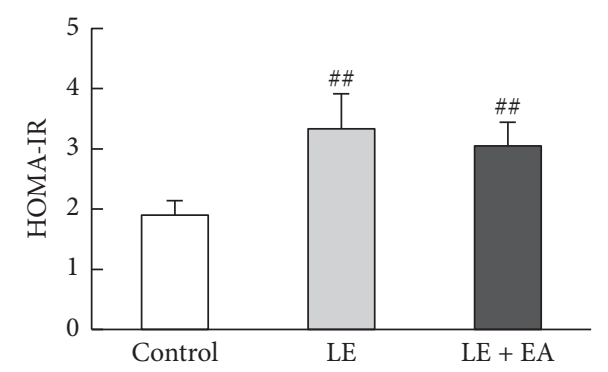

(c)

Figure 5: (a) Levels of free androgen index (FINS), (b) fasting blood glucose (FBG), and (c) HOMA-IR in rats. Error bars represent the SEM, $n=10$ per group. $\# P<0.05$, \#\# $P<0.01$ vs control group; $* P<0.05$ vs LE group.

the mRNA expression of AR and Cx43 was lower in the $\mathrm{LE}+\mathrm{EA}$ group compared to the LE group $(P<0.01$, $P<0.05$ ) (Figure 7).

3.9. Ovarian Protein Expressions of $A R$ and Cx43. Protein expressions of AR and $\mathrm{Cx} 43$ in ovaries were higher in the LE group compared to the control group $(P<0.05)$. In addition, protein levels of AR and Cx43 were lower in the $\mathrm{LE}+\mathrm{EA}$ group compared to the LE group $(P<0.05)$ (Figure 8).

\section{Discussion}

Hyperandrogenism is the basic pathological feature of PCOS and plays an important role in the pathogenesis of PCOS. Androgen excess can lead to a range of clinical symptoms: amenorrhea, hirsutism, acne, and alopecia [37]. In women with PCOS, excess androgens are mainly from the ovaries, and excess androgen synthesis in the ovaries is associated with multiple factors, which may be affected by extraovarian factors such as LH, insulin, neuroendocrine changes, and local factors within the ovary such as INHB and AMH. 


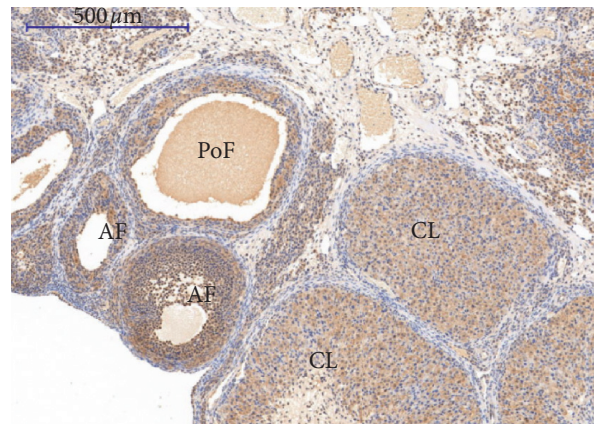

(a)

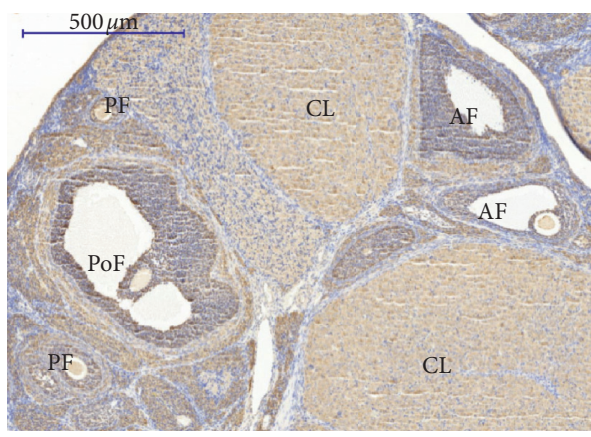

(c)

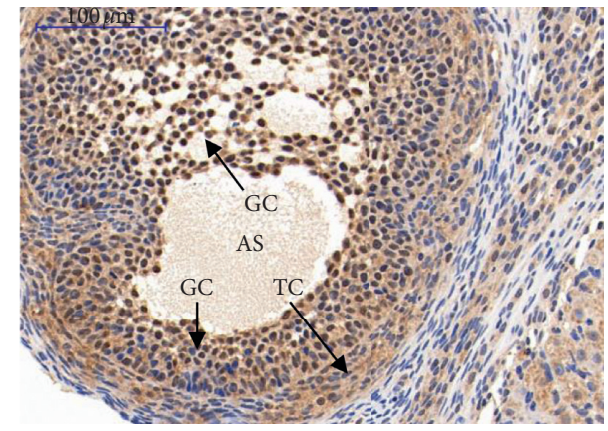

(b)

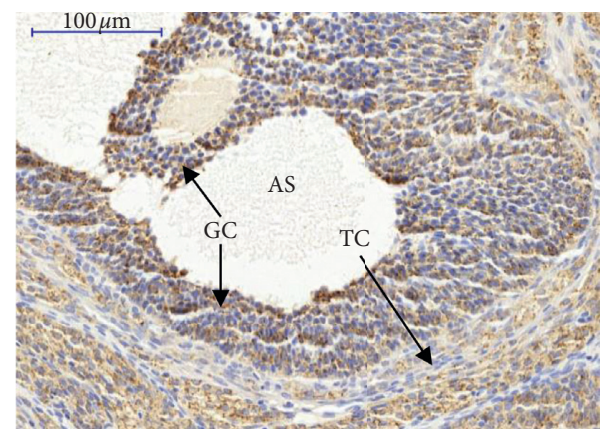

(d)

FIgURE 6: Immunolocalization and expression of the androgen receptor and Connexin43 in the ovary of a control rat. (a-b) Expression and localization of the androgen receptor (AR) in control rat follicles. Positive AR immunostaining was mainly observed in the nuclei of cells at the different developmental stages and corpora lutea (a). Positive AR immunostaining was observed in the nuclei of granulosa cells and theca cells in the antral follicle (b). (c-d) Expression and localization of Cx43 in follicles of control rats. Cx43 was observed as punctuate staining on the borders of granulosa cells in preantral follicles, large antral follicles, preovulatory follicles, and corpora lutea (c). Cx43 displayed punctate to the linear expression on the borders of granulosa cells, between granulosa cells and theca cells, as well as between granulosa cells and oocyte in the preovulatory follicle of control ovary (d). The expression was shown in brown, and the nuclei were stained in blue. PoF, preovulatory follicle; AF, antral follicle; AS, antral space; PF, primary follicle; TC, theca cell; GC, granulosa cell; CL, corpus luteum. Scale bars represent $500 \mu \mathrm{m}$ in (a) and (c). Scale bars represent $100 \mu \mathrm{m}$ in (b) and (d).

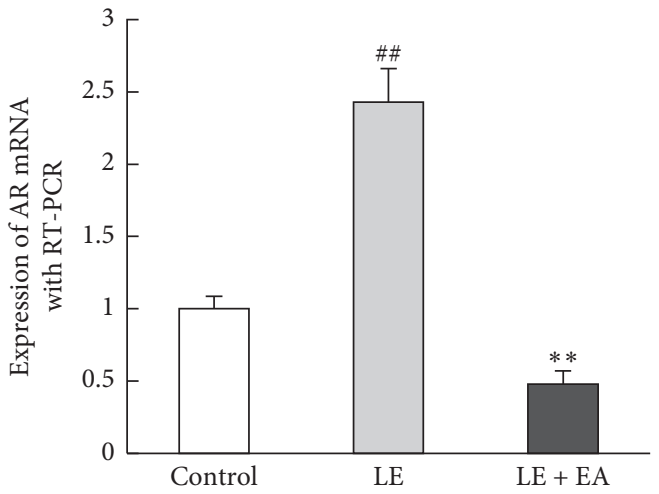

(a)

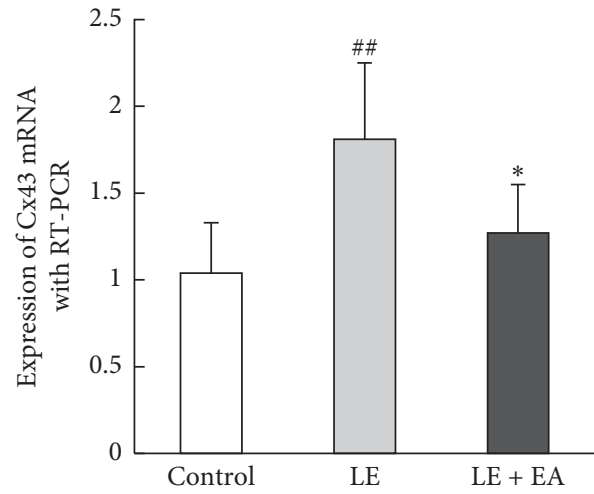

(b)

Figure 7: (a) Effects of EA on mRNA expression levels of AR and (b) Cx43 mRNA in ovarian tissues of rats in the three groups. Values are shown as levels of expression relative to that of Gapdh. Error bars represent the SEM, $n=5$ rats/group, \#\# $P<0.01$; $\# P<0.05$ vs control group; $* * P<0.01 ; * P<0.05$ vs LE group.

Increased expressions of androgen synthesis catalytic enzymes such as cytochrome P45017 $\alpha$ hydroxylase and cytochrome P450 cholesterol side-chain lyase seem to be directly responsible for increased androgen production [38]. Hyperandrogenemia can cause hypothalamus desensitization to the negative feedback of progesterone/ estrogen, thereby further increasing gonadotropin secretion, and increasing the production of ovarian androgens, causing a self-driven vicious cycle. In addition, androgens directly impair follicular development and the formation of 

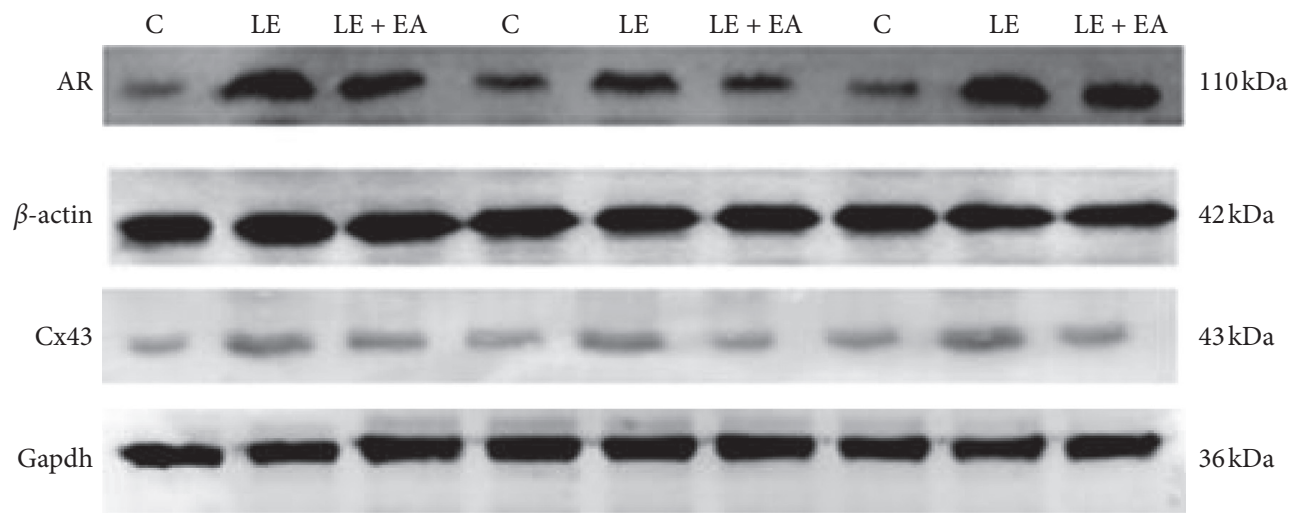

(a)

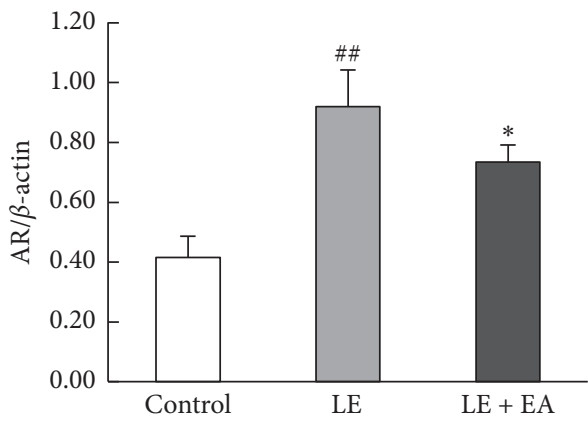

(b)

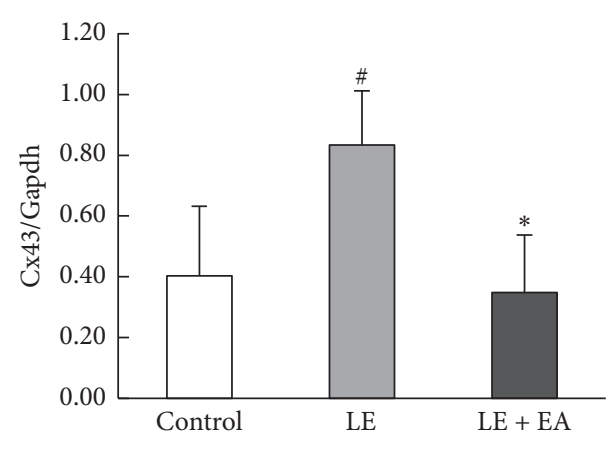

(c)

Figure 8: The effects of EA on AR and Cx43 expression in ovarian tissues of rats in the three groups ( $n=3$ rats/group). (a) Representative immunoblots of AR and Cx43 protein are shown. (b) The bar graph shows the levels of expression relative to that of actin bands in rats' ovarian tissue from three groups. Error bars represent the SEM. \#\# $P<0.01$ vs control group; $* P<0.05$ vs LE group. (c) The bar graph shows the levels of expression relative to that of Gapdh bands in rats' ovarian tissue from three groups. Error bars represent the SEM. \# $P<0.05 \mathrm{vs}$ control group; $* P<0.05$ vs LE group.

dominant follicles, thus leading to the formation of polycystic ovarian morphology [39]. In addition to androgens, IR also affected hypothalamic sensitivity to the negative progesterone feedback, leading to increased gonadotropin secretion. However, the mechanism underlying this effect is unclear $[40,41]$. Hyperinsulinemia can reduce the production of SHBG in the liver and decrease the circulating SHBG levels, thus increasing the level of bioavailable free androgens [42].

In recent studies, it was shown that AMH and INHB were two major ovarian local regulators involved in the pathogenesis of PCOS $[43,44]$. INHB is the major inhibitory factor of FSH secretion and may be involved in the hyporegulation of late follicular FSH. INHB can also increase the synthesis of androgens in follicular thecal cells. It has been shown that INHB can directly promote the expression of P450c17 $\alpha$ and the synthesis of androgens [45]. AMH can reduce the sensitivity of antral follicles to FSH, thereby inhibiting the growth of preantral follicles and small antral follicles. Moreover, $\mathrm{AMH}$ can reduce the synthesis of $\mathrm{E}_{2}$ in granulosa cells by inhibiting the activity of aromatase in the ovary, which results in androgen accumulation. In previous studies, it has been demonstrated that the AMH concentration in serum and follicular fluid in women with PCOS accompanied by hyperandrogenemia was higher compared to that in women with normal androgen levels. These findings showed that $\mathrm{AMH}$ is positively correlated with androgen $[46,47]$.

In our study, we successfully established a rat model of PCOS with the characteristics of polycystic ovaries, obesity, irregular estrous cyclicity, hyperandrogenism, increased plasma insulin levels, decreased plasma SHBG levels, and increased LH concentrations. In addition, we showed that EA could restore the estrous cyclicity and ovary morphology, reduce the body mass of PCOS rats, downregulate plasma levels of T, FAI, LH, and FINS, and upregulate plasma levels of SHBG, $\mathrm{E}_{2}$, and FSH. This animal model also exhibited a significant increase in INHB and AMH. Simultaneously, when compared with the LE group, the $\mathrm{LE}+\mathrm{EA}$ group showed lower INHB and AMH levels. These findings indicated that EA not only directly reduced the expression of androgen synthesis enzymes [17] but also had a benign effect on the factors affecting hyperandrogenism. Increases in blood glucose level, insulin level, and insulin resistance index in PCOS rats indicated that letrozole-induced PCOS rats showed the characteristics of metabolic disorders. EA treatment was found to reduce the insulin level in PCOS rats, had a tendency to reduce insulin resistance index, but had no significant effect on blood glucose levels. A possible explanation for the nonsignificant effect of EA on 
metabolic regulation may be related to acupoint selection, as CV-3 is advocated in TCM theory to mainly regulate reproductive dysfunction.

Androgens activated the AR, a key transcription factor mediating androgen-induced signaling as well as a member of the nuclear receptor. AR-mediated androgen actions played an important role in follicular development. However, it acts as a double-edged sword, and in addition to the positive effects of androgen on follicular development, abnormal androgen levels, especially those found in hyperandrogenism, seriously suppress normal follicular development, and the most typical evidence comes from PCOS [48]. The AR has been shown to be present in all stages of follicular development, with the highest expression levels found in GCs of preantral and small antral follicles [25, 49]. The expression of AR was found to gradually decrease when follicles entered the preovulation stage [32].

Gap junction protein (Connexin, Cx) is the main component of the gap junctions. In ovaries, $\mathrm{Cx} 43$, encoded by Gja1, has been found to be the main Connexin expressed in developing follicles forming the gap junctions coupling granulosa cells [50]. Cx43 is essential to ensure normal proliferation and stratification of granulosa cells and to maintain normal follicular structure and development. Cx43 knockout mice had folliculogenesis arrest in their primary stage and developed incompetent oocytes [27]. Regulation of the expression of GJIC and Connexin protein by steroids has been documented in ovarian cells [51].

Considering the importance of GJIC for GC differentiation and oocyte growth, in addition to the important role of steroids in controlling GJIC, the current study was designed to study the effect of EA on the expression of AR and $\mathrm{Cx} 43$ in PCOS rat ovary. In this study, the expression of $\mathrm{AR}$ and $\mathrm{Cx} 43$ was significantly increased following letrozole administration. This was consistent with the results presented in previous studies, which demonstrate that dihydrotestosterone or androstenedione increased the expression of $\mathrm{Cx} 43$ in ovarian tissues in vivo or in vitro $[33,52]$. However, in a previous study, it was found that AR expression was significantly increased, following testosterone administration (injected intraperitoneally with testosterone at a dose of $1.3 \mathrm{mg} / \mathrm{kg}$ for 7 days), and positive $\mathrm{Cx} 43$ immunostaining was notably weakened in the whole ovary. In preovulatory follicles, Cx43 expression markedly decreased between cumulus granulosa cells and oocytes, whereas $\mathrm{Cx} 43$ expression almost disappeared between granulosa cells as well as between granulosa cells and theca cells [32]. One plausible explanation for this discrepancy may be that different modeling methods and dosages regulated Cx43 expression differentially. In our study, the increased expression of $\mathrm{Cx} 43$ may be associated with the increased number of preantral and small antral follicles in the whole ovary [53]. This partially validated previous findings, demonstrating that $\mathrm{Cx} 43$ had the ability to resist granulosa cell apoptosis [29, 30]. Furthermore, EA treatment decreased the expression of AR, thereby suggesting that EA not only affected the secretion of androgen but also regulated the expression of $A R$. In addition, EA reversed letrozole-induced Cx43 increase.
The results obtained in the present study did not fully support the hypothesis of direct regulation of $\mathrm{Cx} 43$ by androgens but suggested an association between the AR and $\mathrm{Cx} 43$ expression.

Based on the theory of traditional Chinese medicine and experimental studies, we selected acupoints with better therapeutic effects to comprehensively evaluate the therapeutic effect of EA on PCOS rats. The results confirmed the effect of EA on adjusting hormone levels and polycystic ovary morphology in PCOS rats as well as regulating ovarian local factors such as AMH, INHB, AR, or Cx43. In this work, we demonstrated for the first time the EA modulation of Cx43 in letrozole-induced PCOS rats. The limitation of our study was that the underlying mechanism of interaction between $\mathrm{AR}$ and $\mathrm{Cx} 43$ expression and the role of EA were not discussed. Therefore, further studies will be necessary to clarify the underlying mechanism(s) involved.

\section{Conclusions}

In conclusion, our findings indicated the effectiveness of EA in restoring the estrous cyclicity and ovary morphology and regulating circulating sex hormone levels and hyperinsulinemia in rats with letrozole-induced PCOS. Furthermore, EA normalized the letrozole-induced upregulation of AR and Cx43. Taken together, these results suggested that acupuncture may be an effective treatment method to improve the reproductive and endocrine dysfunction resulting from PCOS and could break the vicious cycle initiated by excessive androgen secretion. Guan yuan was the first acupoint to be considered in the treatment of PCOS.

\section{Abbreviations}

$\begin{array}{ll}\text { PCOS: } & \text { Polycystic ovarian syndrome } \\ \text { T: } & \text { Testosterone } \\ \mathrm{E}_{2}: & \text { Estradiol } \\ \text { FSH: } & \text { Follicle-stimulating hormone } \\ \text { LH: } & \text { Luteinizing hormone } \\ \text { FAI: } & \text { Free androgen index } \\ \text { SHBG: } & \text { Sex hormone-binding globin } \\ \text { FINS: } & \text { Fasting serum insulin } \\ \text { FBG: } & \text { Fasting blood glucose } \\ \text { HOMR-IR: } & \text { Homeostasis model-insulin resistance } \\ \text { AMH: } & \text { Anti-Müllerian hormone } \\ \text { INHB: } & \text { Inhibin B } \\ \text { AR: } & \text { Androgen receptor } \\ \text { Cx43: } & \text { Connexins 43 } \\ \text { EA: } & \text { Electroacupuncture } \\ \text { ELISA: } & \text { Enzyme-linked immunosorbent assay } \\ \text { IVF: } & \text { In vitro fertilization } \\ \text { LE: } & \text { Letrozole. }\end{array}$

\section{Data Availability}

The datasets used and/or analyzed in the current study are available from the corresponding author upon reasonable request. 


\section{Ethical Approval}

All experimental protocols used in this study were approved by the Animal Ethical Committee of Shanghai University of Chinese Traditional Medicine (Shanghai, China) and were in accordance with the ethical standards of the committee.

\section{Conflicts of Interest}

The authors declare that they have no conflicts of interest.

\section{Authors' Contributions}

Ge Xu participated in the design of the study, supervised the animal studies, participated in animal preparation and blood flow measurements, performed the statistical analysis, and wrote the manuscript. Xi Wang, Andong Zhang, Jian-Dang Liu, and Ji Wei Feng participated in animal experiments. Yuelai Chen contributed to the design of the study and supervised all the work performed. All authors read and approved the final manuscript.

\section{Acknowledgments}

The authors thank all the individuals and institutions for their contributions to this study. This study was supported by the Shanghai Municipal Doctoral Programs Foundation (B201407).

\section{References}

[1] E. S. Knouchenhauer, T. J. Key, M. Kahsar-Miller, W. Waggoner, and L. R. Boots, "Prevalence of the polycystic ovary syndrome in unselected black and white women of the southeastern United States: a prospective study," Journal of Clinical Endocrinology \& Metabolism, vol. 83, no. 9, pp. 3078-3082, 1998.

[2] M. Asuncion, R. M. Calvo, J. L. San Millan, J. Sancho, and S. Avila, "A prospective study of the prevalence of the polycystic ovary syndrome in unselected Caucasian women from Spain," Journal of Clinical Endocrinology \& Metabolism, vol. 85, no. 7, pp. 2434-2438, 2000.

[3] R. Li, Q. Zhang, D. Yang et al., "Prevalence of polycystic ovary syndrome in women in China: a large community-based study," Human Reproduction, vol. 28, no. 9, pp. 2562-2569, 2013.

[4] B. O. Yildiz, G. Bozdag, Z. Yapici, I. Esinler, and H. Yarali, "Prevalence, phenotype and cardiometabolic risk of polycystic ovary syndrome under different diagnostic criteria," Human Reproduction, vol. 27, no. 10, pp. 3067-3073, 2012.

[5] D. A. Dumesic, S. E. Oberfield, E. Stener-Victorin et al., "Scientific statement on the diagnostic criteria, epidemiology, pathophysiology, and molecular genetics of polycystic ovary syndrome," Endocrine Reviews, vol. 36, no. 5, pp. 487-525, 2015.

[6] A. Dunaif, "Insulin resistance and the polycystic ovary syndrome: mechanism and implications for pathogenesis," Endocrine Reviews, vol. 18, no. 6, pp. 774-800, 1997.

[7] E. Dahlgren, P. O. Janson, S. Johansson, L. Lapidus, G. Lindstedt, and L. Tengborn, "Hemostatic and metabolic variables in women with polycystic ovary syndrome," Fertility and Sterility, vol. 61, no. 3, pp. 455-460, 1994.
[8] V. L. Nelson, K.-N. Qin, R. L. Rosenfield et al., "The biochemical basis for increased testosterone production in theca cells propagated from patients with polycystic ovary syndrome," The Journal of Clinical Endocrinology \& Metabolism, vol. 86, no. 12, pp. 5925-5933, 2001.

[9] Y. Wu, N. Robinson, P. J. Hardiman et al., “Acupuncture for treating polycystic ovary syndrome: guidance for future randomized controlled trials," Journal of Zhejiang UniversityScience B, vol. 17, no. 3, pp. 169-180, 2016.

[10] L. N. Ren, L. H. Guo, and W. Z. Ma, "A meta-analysis on acupuncture treatment of polycystic ovary syndrome," Acupuncture Research, vol. 39, pp. 238-246, 2014.

[11] B. Z. Yang, W. Cui, and J. Li, "Effects of electroacupuncture intervention on changes of quality of ovum and pregnancy outcome in patients with polycystic ovarian syndrome," Acupuncture Research, vol. 40, pp. 151-156, 2015.

[12] L. M. Pastore, C. D. Williams, J. Jenkins, and J. T. Patrie, "True and sham acupuncture produced similar frequency of ovulation and improved LH to FSH ratios in women with polycystic ovary syndrome," The Journal of Clinical Endocrinology \& Metabolism, vol. 96, no. 10, pp. 3143-3150, 2011.

[13] Y. Feng, J. Johansson, R. Shao et al., "Hypothalamic neuroendocrine functions in rats with dihydrotestosterone-induced polycystic ovary syndrome: effects of low-frequency electroacupuncture," PLoS One, vol. 4, no. 8, Article ID e6638, 2009.

[14] Y. Feng, J. Johansson, R. Shao, L. M. Holm, H. Billig, and E. Stener-Victorin, "Electrical and manual acupuncture stimulation affect oestrous cyclicity and neuroendocrine function in an $5 \alpha$-dihydrotestosterone-induced rat polycystic ovary syndrome model," Experimental Physiology, vol. 97, no. 5, pp. 651-662, 2012.

[15] M. Maliqueo, A. Benrick, A. Alvi et al., "Circulating gonadotropins and ovarian adiponectin system are modulated by acupuncture independently of sex steroid or $\beta$-adrenergic action in a female hyperandrogenic rat model of polycystic ovary syndrome," Molecular and Cellular Endocrinology, vol. 412, pp. 159-169, 2015.

[16] E. Stener-Victorin and C. Lindholm, "Immunity and $\beta$-endorphin concentrations in hypothalamus and plasma in rats with steroid-induced polycystic ovaries: effect of low-frequency electroacupuncture," Biology of Reproduction, vol. 70, no. 2, pp. 329-333, 2004.

[17] J. Sun, C. Jin, H. Wu et al., "Effects of electro-acupuncture on ovarian P450arom, $\mathrm{P} 450 \mathrm{c} 17 \alpha$ and mRNA expression induced by letrozole in PCOS rats," PLoS One, vol. 8, no. 11, pp. 1-8, 2013.

[18] J. Johansson, L. Redman, P. P. Veldhuis et al., "Acupuncture for ovulation induction in polycystic ovary syndrome: a randomized controlled trial," American Journal of Physiology Endocrinology \& Metabolism, vol. 304, no. 9, pp. 934-943, 2013.

[19] A. Dunaif, "Insulin resistance and the polycystic ovary syndrome: mechanism and implications for pathogenesis," Endocrine Reviews, vol. 18, no. 6, pp. 774-800, 1997.

[20] E. Carmina and R. A. Lobo, "Use of fasting blood to assess the prevalence of insulin resistance in women with polycystic ovary syndrome," Fertility and Sterility, vol. 82, no. 3, pp. 661-665, 2004.

[21] F. Liang and D. Koya, "Acupuncture: is it effective for treatment of insulin resistance?" Diabetes Obesity \& Metabolism, vol. 12, no. 7, pp. 555-569, 2009.

[22] S.-L. Chang, C.-C. Tsai, J.-G. Lin, C.-L. Hsieh, R.-T. Lin, and J.-T. Cheng, "Involvement of serotonin in the hypoglycemic response to $2 \mathrm{~Hz}$ electroacupuncture of zusanli acupoint 
(ST36) in rats," Neuroscience Letters, vol. 379, no. 1, pp. 69-73, 2005.

[23] S.-L. Chang, K.-J. Lin, R.-T. Lin, P.-H. Hung, J.-G. Lin, and J.-T. Cheng, "Enhanced insulin sensitivity using electroacupuncture on bilateral zusanli acupoints (ST 36) in rats," Life Sciences, vol. 79, no. 10, pp. 967-971, 2006.

[24] L. Manners, I. H. Jonsdottir, A. Holmäng, M. Lonn, and E. Stener-Victorin, "Low-frequency electro-acupuncture and physical exercise improve metabolic disturbances and modulate gene expression in adipose tissue in rats with dihydrotestosterone-induced polycystic ovary syndrome," Endocrinology, vol. 149, no. 7, pp. 3559-3568, 2008.

[25] J. L. Juengel, D. A. Heath, L. D. Quirke, and K. P. McNatty, "Oestrogen receptor $\alpha$ and $\beta$, androgen receptor and progesterone receptor mRNA and protein localisation within the developing ovary and in small growing follicles of sheep," Reproduction, vol. 131, no. 1, pp. 81-92, 2006.

[26] G. X. Pan, L. Y. Shi, and A. Y. Luo, "Androgen receptor in ovary: a review of current literature," Maternal and Child Health Care of China, vol. 30, pp. 5931-5933, 2015.

[27] C. L. Ackert, J. E. I. Gittens, M. J. O’Brien, J. J. Eppig, and G. M. Kidder, "Intercellular communication via connexin 43 gap junctions is required for ovarian folliculogenesis in the mouse," Developmental Biology, vol. 233, no. 2, pp. 258-270, 2001.

[28] S. C. Juneja, K. J. Barr, G. C. Enders, and G. M. Kidder, "Defects in the germ line and gonads of mice lacking connexin431," Biology of Reproduction, vol. 60, no. 5, pp. 1263-1270, 1999.

[29] J. H.-C. Lin, J. Yang, S. Liu et al., "Connexin mediates gap junction-independent resistance to cellular injury," The Journal of Neuroscience, vol. 23, no. 2, pp. 430-441, 2003.

[30] D. V. Krysko, S. Mussche, L. Leybaert, and K. D’Herde, “Gap junctional communication and connexin 43 expression in relation to apoptotic cell death and survival of granulosa cells," Journal of Histochemistry \& Cytochemistry, vol. 52, no. 9, pp. 1199-1207, 2004.

[31] C.-T. Lee, J.-Y. Wang, K.-Y. Chou, and M.-I. Hsu, "1,25dihydroxyvitamin D3 increases testosterone-induced 17beta-estradiol secretion and reverses testosterone-reduced connexin 43 in rat granulosa cells," Reproductive Biology and Endocrinology, vol. 12, no. 1, p. 90, 2014.

[32] M. Yang, J. Li, Y. An, and S. Zhang, "Effects of androgen on immunohistochemical localization of androgen receptor and connexin 43 in mouse ovary," Tissue and Cell, vol. 47, no. 5, pp. 526-532, 2015.

[33] R. Talhouk, C. Tarraf, L. Kobrossy et al., "Modulation of Cx43 and gap junctional intercellular communication by androstenedione in rat polycystic ovary and granulosa cells in vitro," Journal of Reproduction \& Infertility, vol. 13, pp. 21-32, 2012.

[34] R. Chen, L. Yang, Z. Liu et al., "AR pathway is involved in the regulation of CX43 in prostate cancer," Biomed Research International, vol. 2015, Article ID 514234, 6 pages, 2015.

[35] H. Kafali, M. Iriadam, I. Ozardalı, and N. Demir, "Letrozoleinduced polycystic ovaries in the rat: a new model for cystic ovarian disease," Archives of Medical Research, vol. 35, no. 2, pp. 103-108, 2004.

[36] G. Xu, X. Wang, A. D. Zhang et al., "Effects of electroacupuncture at different acupoints on hyperandrogenism and expression of androgen receptor in the ovary of PCOS rats," Acupuncture Research, vol. 9, pp. 543-549, 2018.

[37] R. Azziz, E. Carmina, D. Dewailly et al., "Criteria for defining polycystic ovary syndrome as a predominantly hyperandrogenic syndrome: an androgen excess society guideline," The Journal of
Clinical Endocrinology \& Metabolism, vol. 91, no. 11, pp. 4237-4245, 2006.

[38] D. A. Magoffin, "Ovarian enzyme activities in women with polycystic ovary syndrome," Fertility \& Sterility, vol. 86, no. 1, pp. 9-11, 2006.

[39] V. Nisenblat and R. J. Norman, "Androgens and polycystic ovary syndrome," Current Opinion in Endocrinology, Diabetes and Obesity, vol. 16, no. 3, pp. 224-231, 2009.

[40] S. K. Blank, C. R. McCartney, S. Chhabra et al., "Modulation of gonadotropin-releasing hormone pulse generator sensitivity to progesterone inhibition in hyperandrogenic adolescent girls-implications for regulation of pubertal maturation," The Journal of Clinical Endocrinology \& Metabolism, vol. 94, no. 7, pp. 2360-2366, 2009.

[41] F. Tosi, C. Negri, F. Perrone et al., "Hyperinsulinemia amplifies GnRH agonist stimulated ovarian steroid secretion in women with polycystic ovary syndrome," The Journal of Clinical Endocrinology \& Metabolism, vol. 97, no. 5, pp. 1712-1719, 2012.

[42] R. Pasquali and F. Casimirri, "The impact of obesity on hyperandrogenism and polycystic ovary syndrome in premenopausal women," Clinical Endocrinology, vol. 39, no. 1, pp. 1-16, 1993.

[43] B. Tata, N. E. H. Mimouni, A.-L. Barbotin et al., "Elevated prenatal anti-müllerian hormone reprograms the fetus and induces polycystic ovary syndrome in adulthood," Nature Medicine, vol. 24, no. 6, pp. 834-846, 2018.

[44] Q. Liu, D. Y. li, D. Zhao et al., "Significance of INHB level changes in PCOS patients in the process of controlled superovulation," Journal of Laboratory Medicine and Clinical Practice, vol. 14, no. 17, pp. 2597-2599, 2017.

[45] A. L. Chand, C. A. Harrison, and A. N. Shelling, "Inhibin and premature ovarian failure," Human Reproduction Update, vol. 16, no. 1, pp. 39-50, 2010.

[46] M. Das, D. J. Gillott, E. Saridogan, and O. Djahanbakhch, "Anti-mullerian hormone is increased in follicular fluid from unstimulated ovaries in women with polycystic ovary syndrome," Human Reproduction, vol. 23, no. 9, pp. 2122-2126, 2008.

[47] P. Pigny, E. Merlen, Y. Robert et al., "Elevated serum level of anti-mullerian hormone in patients with polycystic ovary syndrome: relationship to the ovarian follicle excess and to the follicular arrest," The Journal of Clinical Endocrinology \& Metabolism, vol. 88, no. 12, pp. 5957-5962, 2003.

[48] J.-X. Pan, J.-Y. Zhang, Z.-H. Ke et al., “Androgens as doubleedged swords: induction and suppression of follicular development," Hormones, vol. 14, no. 2, pp. 190-200, 2015.

[49] S. G. Hillier, M. Tetsuka, and H. M. Fraser, "Location and developmental regulation of androgen receptor in primate ovary," Human Reproduction, vol. 12, no. 1, pp. 107-111, 1997.

[50] D. Tong, J. E. I. Gittens, G. M. Kidder, and D. Bai, "Patchclamp study reveals that the importance of connexin43-mediated gap junctional communication for ovarian folliculogenesis is strain specific in the mouse," American Journal of Physiology-Cell Physiology, vol. 290, no. 1, pp. C290-C297, 2006.

[51] R. Grümmer, O. Traub, and E. Winterhager, "Gap junction connexin genes cx26 and cx43 are differentially regulated by ovarian steroid hormones in rat endometrium," Endocrinology, vol. 140, no. 6, pp. 2509-2516, 1999.

[52] H. Jing, The Expression of Cx43 in Mouse Ovary and Effects of Luteinizing Hormone and Dihydrotestosterone on the Expression of Cx43 in Mouse Ovary and Rat Granulosa Cells, Ningxia Medical University, Ningxia, China, 2017. 
[53] G. Xu, A. D. Zhang, X. Wang et al., "Effects of electroacupuncture at different acupoints on follicle development and relative factors in the ovary of PCOS rats," Acupuncture Research, vol. 44, no. 10, pp. 740-746, 2019. 